\title{
Design Thinking: The Power of Customer-centric Approach to Problem Solving
}

\author{
Rozalia Nistor \\ rozalia.nistor@ugal.ro \\ Mihaela-Carmen Muntean \\ mihaela.muntean@,ugal.ro \\ Ludmila Daniela Manea \\ manealudmiladaniela@gmail.com \\ Florina Oana Virlanuta \\ florinaoana27@yahoo.com
}

Dunarea de Jos University of Galati, Romania

"To bave a great idea ... have a lot of them."

Thomas Edison

Or

"Creativity is just having enough dots to connect... ... to connect experiences and synthesize new things. The reason creative people are able to do that is that they've had more experiences or have thought more about their experiences than other people."

\begin{abstract}
Design thinking utilizes elements from the designer's toolkit like empathy and experimentation to arrive at innovative solutions. By using design thinking, you make decisions based on what future customers really want instead of relying only on historical data or making risky bets based on instinct instead of evidence. Thinking like a designer can transform the way organizations develop products, services, processes, and strategy. Design thinking has a human-centered core. It encourages organizations to focus on the people they're creating for, which leads to better products, services, and internal processes. When you sit down to create a solution for a business need, the first question should always be what's the human need behind it? Getting to know your customers is the first step toward creating products and services they want and need. Don't assume you know what someone thinks or feels. Gathering information about your target consumer is a critical piece of the design thinking approach. When design principles are applied to strategy and innovation, the success rate for innovation dramatically improves.
\end{abstract}

Key words: mainstream customer; lead users; latent need; design thinking; innovation, creativity, fast loan

\section{Introduction}

We all live a silent revolution of great transformations. Somehow, we know that technology has changed our lives and will make it even more so. Some of us even know that new technologies will lead to the disappearance of many jobs. Of course, these huge changes are at the level of the whole world and we will find some way to cope with the changes that are coming. But we must certainly ask ourselves how to become less superficial and how to bring about change for the better, meaningful to others, to the organizations we work for and, implicitly, to ourselves. An interesting starting point is the design itself

The design started modestly, from the time we lived in caves and created tools to simplify our existence. Therefore, "design is everything around us, everything created by man, whether it was made conscious or not." 
Design Thinking is actually a methodology, as is project management. But there is also a philosophy, which comes with a set of methods and techniques borrowed from the design toolkit. Design Thinking is, therefore, the basis for borrowing the way good designers approach problems, which can be applied in any context, be it social, business, career, environmental or personal. The concept of Design Thinking appeared in 1987, by Peter Rowe, professor of architecture and urban design at Harvard, in his book Design Thinking. In fact, design-specific thinking actually applies as early as the 1970s, before being theorized. However, the explosion of interest to the general public began in the 1990s, through its promotion by David Kelley, a professor at Stanford Design School and co-founder of the design and consulting company IDEO.

Design Thinking was adopted and adapted to Stanford and then spread like fire in a forest with dry vegetation. The great attraction for Design Thinking is explained, in part because it has brought many results, also for companies, and for organizations with social projects. And it can be applied for any challenge. From the creation of a new hammock model, to attracting young people to the Opera or rethinking how a department works in a company.

Design Thinking is not like the science of rocket building. It has been shaped as a methodology by successful designers who have separated from others with a different mindset and approach to the rest of the world. And this mentality is centered on empathy and prototyping and embracing failure. Good designers do not get stuck in the way most of us approach problems linearly. They do not do so: they establish the problem, generate more ideas, analyze them and choose one, as the correct one.

Designers feed on ambiguity and are not afraid to make mistakes, receive feedback and come up with new solutions to create something truly valuable.

The paper is structured in 5 sections, each of them addressing theories on the concept of Design Thinking, analysis of the Design Thinking methodology and a study case of Design Thinking application. The first chapter "Introduction" presents the topic on the subject. The second chapter, entitled "Design thinking, an efficient way for a systematic innovation of products, services and business processes", is dedicated to the definition of essential terms and aims to define Design Thinking by mentioning its importance in the economy, concepts and factors of influence. Chapter 3 "Design Thinking methodology" presents the Design Thinking in the company's activities, the interpretation of the phenomenon as well as the factors of influence. The fourth chapter "The Study case" presents the application of the Design Thinking in the approval and disbursal of bank loans to individual within 24 Hours. The paper ends with a series of Conclusions.

\section{Design thinking, an efficient way for a systematic innovation of products, services and business processes}

There are already many ways to name and explain the methodology of design thinking. The methodology promoted by IDEO (a global design and innovation company) is the one most often referred to. It consists of 5 non-linear stages, namely: empathise - define the problem ideate - prototype - test.

\section{Empathise}

The first stage of the Design Thinking process is to gain an empathic understanding of the problem you are trying to solve. This involves consulting experts to find out more about the area of concern through observing, engaging and empathizing with people to understand their experiences and motivations, as well as immersing yourself in the physical environment so you can gain a deeper personal understanding of the issues involved. Empathy is crucial to a humancentered design process such as Design Thinking, and empathy allows design thinkers to set aside their own assumptions about the world in order to gain insight into users and their needs.

Depending on time constraints, a substantial amount of information is gathered at this stage to use during the next stage and to develop the best possible understanding of the users, their needs, and the problems that underlie the development of that particular product. 


\section{Define (the Problem)}

During the Define stage, you put together the information you have created and gathered during the Empathise stage. This is where you will analyse your observations and synthesise them in order to define the core problems that you and your team have identified up to this point. You should seek to define the problem as a problem statement in a human-centred manner.

\section{Ideate}

During the third stage of the Design Thinking process, designers are ready to start generating ideas. You've grown to understand your users and their needs in the Empathise stage, and you've analysed and synthesised your observations in the Define stage, and ended up with a humancentered problem statement. With this solid background, you and your team members can start to "think outside the box" to identify new solutions to the problem statement you've created, and you can start to look for alternative ways of viewing the problem. There are hundreds of Ideation techniques such as Brainstorm, Brainwrite, Worst Possible Idea, and SCAMPER. Brainstorm and Worst Possible Idea sessions are typically used to stimulate free thinking and to expand the problem space. It is important to get as many ideas or problem solutions as possible at the beginning of the Ideation phase. You should pick some other Ideation techniques by the end of the Ideation phase to help you investigate and test your ideas so you can find the best way to either solve a problem or provide the elements required to circumvent it.

\section{Prototype}

The design team will now produce a number of inexpensive, scaled down versions of the product or specific features found within the product, so they can investigate the problem solutions generated in the previous stage. Prototypes may be shared and tested within the team itself, in other departments, or on a small group of people outside the design team. This is an experimental phase, and the aim is to identify the best possible solution for each of the problems identified during the first three stages. The solutions are implemented within the prototypes, and, one by one, they are investigated and either accepted, improved and re-examined, or rejected on the basis of the users' experiences. By the end of this stage, the design team will have a better idea of the constraints inherent to the product and the problems that are present, and have a clearer view of how real users would behave, think, and feel when interacting with the end product.

\section{Test}

Designers or evaluators rigorously test the complete product using the best solutions identified during the prototyping phase. This is the final stage of the 5 stage-model, but in an iterative process, the results generated during the testing phase are often used to redefine one or more problems and inform the understanding of the users, the conditions of use, how people think, behave, and feel, and to empathise. Even during this phase, alterations and refinements are made in order to rule out problem solutions and derive as deep an understanding of the product and its users as possible.

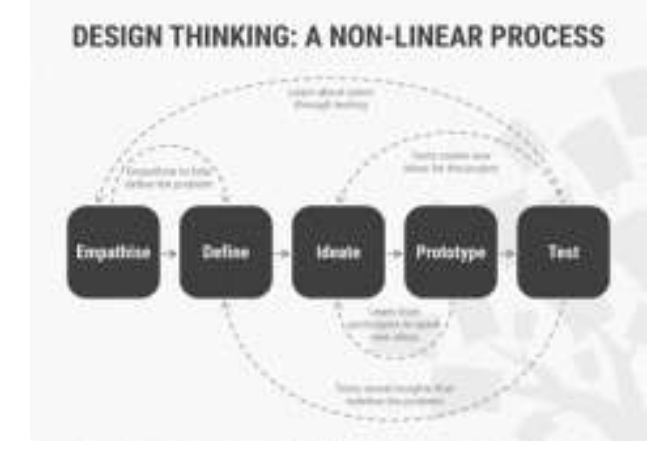

Figure 1. 5 phases of the design thinking process

In his 1969 seminal text on design methods, "The Sciences of the Artificial," Nobel Prize laureate Herbert Simon outlined one of the first formal models of the Design Thinking process. Simon's 
model consists of seven major stages, each with component stages and activities, and was largely influential in shaping some of the most widely used Design Thinking process models today. There are many variants of the Design Thinking process in use in the 21st century, and while they may have different numbers of stages ranging from three to seven, they are all based upon the same principles featured in Simon's 1969 model. We focus on the five-stage Design Thinking model proposed by the Hasso-Plattner Institute of Design at Stanford.

The overall purpose of Design Thinking is to help you to design better products, services, processes, strategies, spaces, architecture and experiences. It helps you to develop practical and innovative solutions to the problems you see in your department or company. It is a relevant process in a user-centered paradigm, as it is today

The method is just theory without the tools that put Design Thinking into practice. There are many tools and exercises available, specific to each stage of the process.

The following are examples of popular exercises for each stage:

- Participant Observation or Shadowing (Discover) is a research method to understand situations and behaviours. The team members become participants who immerse themselves in the subject they are studying. They become "detectives" trying to learn as much about the behaviour and environment of users.

- Journey Mapping (Describe) is a visual tool that team members use to map detailed research over a given period of time. Such a representation makes it possible to identify weaknesses or problems that the user may encounter. Key points that can trigger innovation opportunities can easily be highlighted.

- Concept Poster (Ideate \& Prototype) is meant to encourage team members to think with their hands. By creating a poster, you can make overviews and enough details to make a decision about moving the concept to the next level.

- Desirability Testing (Test) is a method used to quickly understand users' emotional reactions to the proposed solution. External participants are invited to express their feelings about the proposed solution based on relevant, pre-defined categories (eg. appearance, ease of use, speed)

- Concept Prototyping (Implement) is a method that ends with a realistic representation of the concept. Depending on the time frame and budget available, prototypes can be created from paper, LEGO or real objects.

We use Design Thinking as a way to identify creative and innovative solutions for internal initiatives, but also to help clients overcome their challenges.

This can be done in the form of a workshop. Depending on the complexity and area of definition, the duration may vary from a few days to several weeks. The concept of a workshop, together with detailed and customized planning are managed by a Design Thinking instructor / facilitator, always having the final goal. The workshop will go through all the steps of the Design Thinking process, but it can also be customized to focus only on certain stages.

Some of the benefits of Design Thinking are:

- Can be applied in all fields and industries for both products and services;

- Provides a framework for working with clients in order to identify innovative ideas and help them think differently;

- Allows fragmentation of complex problems and visualization of opportunities;

- Encourages spending time to understand the true problem.

In the digital age when all trends are focused on personalized services and products for the user, a method of solving problems such as user-centered Design Thinking is more relevant than ever. Renowned companies such as P\&G, Pepsi, SAP, Coca-Cola and IBM cultivate Design Thinking as a management philosophy, in an effort to remain relevant in a business reality that is facing increasingly complex and ambiguous issues, in a world almost impossible to predict, and in which customers expect personalized and authentic products, services and experiences from companies. AG Lafley, the CEO of P\&G who transformed the company in the 2000s, in his book "The Game Changer" says of design schools that "stands out by cultivating abductive thinking, which 
guides us toward finding possibilities, in contrast to traditional schools. Business that teaches us to think inductively (based on what we can observe) and deductive (through logic and analysis, usually based on something that happened)". Lafley believes that "this new type of thinking (in business) helps us to question our own perceptions about constraints and invites us to build on new ideas rather than discourage them".

The Design Institute of the United States publishes the Design Value Index annually. In 2016 it showed us that those companies that integrated design thinking into their business practice, exceeded in financial performances by $211 \%$ those of the 'Standard \& Poor' Index. How is this possible?

Strong consumer empathy, multidisciplinarity and willingness to try and test new ideas quickly and in a practical way helps these companies better tolerate and navigate ambiguity and risk, but above all, stay focused on people's true needs.

\section{Design Thinking methodology}

Design Thinking is a design methodology that provides a solution-based approach to solving problems. It's extremely useful in tackling complex problems that are ill-defined or unknown, by understanding the human needs involved, by re-framing the problem in human-centric ways, by creating many ideas in brainstorming sessions, and by adopting a hands-on approach in prototyping and testing.

Design thinking creates a systematic process of innovation for products and services, based on identifying customer needs and latent needs, and unaddressed needs. To start working on innovation it is useful to think about three dimensions: people dimension, the technical dimension, and the business dimension, three different challenges that make products and services successful if they are truly innovative. Innovations have to solve those three challenges, creating opportunities and developing a solution that can address all three (method Real-WinWorth It)

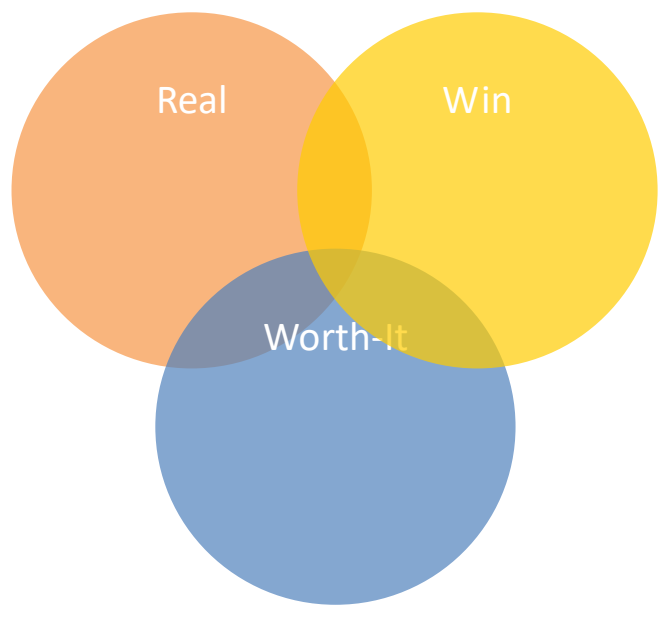

Figure 2. The Real-Win-Worth It Method

The Real-Win-Worth-It analysis should be able to answers to many questions: Is the opportunity real? How big is the market, the customers, the segments? Is there a real unmet need? Can we win? Do we have a better/smarter solution? Can we deliver it? Is there a way to do that would give us a competitive advantage?

Based on the MIT perspective, each component of the RWW model have the following approach:

- Real means people "desirable", in this stage of analysis we can find out if the opportunity or solution is real or not 
- Win or business "viable" in this stage of analysis we analyse the solution from the business perspective.

- Worth-It or technical "feasible", in this stage of analysis we can check if the solution is feasible

Customers would be willing to pay something to have us help them to solve their problems (latent need) and so the people dimension is the product, the solution, has to be desirable. People have to feel and know they have that need. Sometimes that takes some work before they can actually recognize that they have that need but it has to be addressing some need or people will not buy it, they will not desire our product or service.

The second dimension is the technical dimension. We have to be able to solve this problem in a technically feasible way. Some technical, technically feasible solutions are very, very difficult to do and maybe we do not have the resources to solve them and others we can. So we have to be able to solve it in the way that is technically, that technically works for those customers in the, whatever the use environment might be.

A business that does not, cannot have enough revenue in order to pay for the costs, we can't do that for very long. So by a viable business we mean generally one that can make some profit in order to pay back all the investment and there's got to be some business model, some business model that explains how that works.

If we only do one or two of them, we generally cannot have a successful innovation. On the other hand, we do not need to solve them all at once. We need to solve them all eventually, that is, you might start from the people dimension or maybe we start from a new innovative business model and we are quite sure that can make work, and then eventually we solve the other dimensions.

Designers, people who innovate new products and services, have a certain set of skills, and these skills transcend the different types of design. Successful software designers, hardware designers, graphic designers, mechanical engineers, people who are good at creating successful innovations have a certain set of skills, or habits that have been lately, "design thinking."

The first thing about design thinking is, success designers know they can't do it all at once. We talk about different phases. The MIT's approach describe three stages of design thinking methodology: the explore phase; the creation, and the implementation of those solutions.

The first step is about design thinking skills which means work together to create a systematic process of innovation for products and services

The second step is about understanding customers, or identifying customer needs and latent needs, and unaddressed needs.

The third step, is about creativity, brainstorming, and some of the good methods around making that an effective process for generating a wide range of solutions to the problem at hand..

The fourth step is about designing good/services or how exactly are products and services different? What are some of the techniques that need to change in the development process?

The fifth step is about financial analysis. Specifically, how do we take the methods around time value of money, net present value, and discounted cash flow? We will use them to evaluate product development projects.

The sixth step will look at the impact of the products and services that we design and use on the environment. We will look at environmental sustainability and what are some of the ways I would like you to learn to think about making decisions better in the design process in order to reduce environmental impact.

\section{A. Identifying customer needs}

Each product addresses a 'latent need' that were not previously aware of (thereby making it innovative). Identification and analysis of customer needs is a part of the concept development process which begins the overall product development process. 


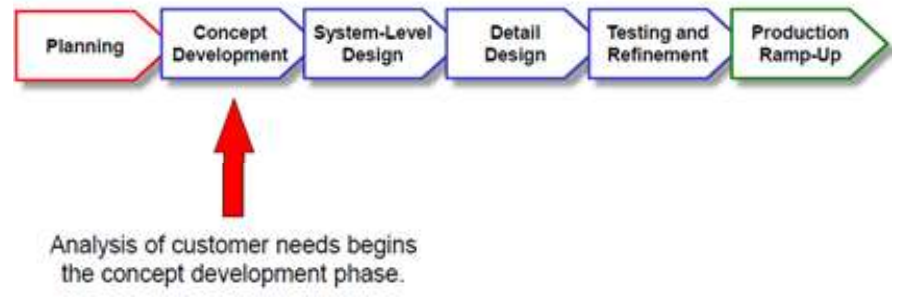

Figure 3. Product Development Process

To analyse customer needs we need to understand that there are different markets or segments of customers. Generally, we think of the mainstream customers, the big market segment. This chart now shows how as - how different markets have different needs. So the mainstream customers, well, they are mainstream, they are the biggest segment because they have a common set of needs.

A large group of people with the same needs. In addition, it is natural to look at that market and try to address those needs, and we should do that. However, there are two special types of customers who have more specific sets of needs, and if we can understand their needs, we can get a real advantage. In addition, these types of customers are called lead users and extreme users. Lead users are customers who experience the need a little bit in advance of the mainstream market. Moreover, the reason they do so is that they use that product or service in their daily lives, in their business, in their livelihood. Secondly, those lead users, they would benefit from improvements in the product. Costumer with specific needs may be in small market segments, but their needs may indicate important directions for larger markets.

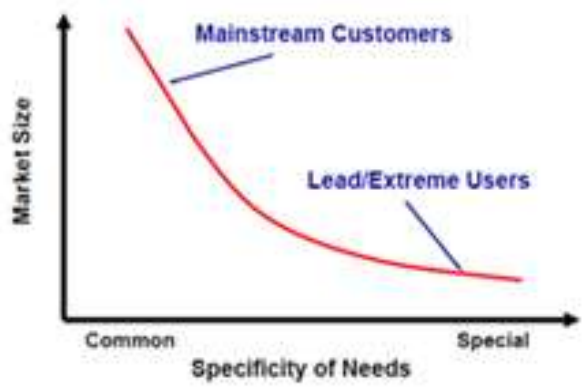

Figure 4. Customer needs and markets

\section{B. Applied creativity/product concept generation}

First, we have to do the distinction between Invention, Innovation, and Creativity, which often are used improperly or interchangeably:

- Invention, creation of something that didn't exist before

- Innovation reflect in an useful application of an invention or combining existing ideas in a new and useful way

- Creativity mirror in application of imagination to a problem

The most commonly used method for applied creativity is the brainstorming method. The original work on brainstorming was from the 1940's. Alex Osborn (an advertising executive) who realized that there are approaches that work to developing creative ideas, and he called that brainstorming. He wrote books about this process back in the '40's and '50's and ran a research group to develop some of these ideas and approaches.

Now, here is our concept development process again. We will see we are working now on the step, which is called concept generation. So after we have customer needs, a good list, maybe turn those into target specifications as we have discussed. We next turn to finding solutions. In addition, that is what is called typically concept generation. 


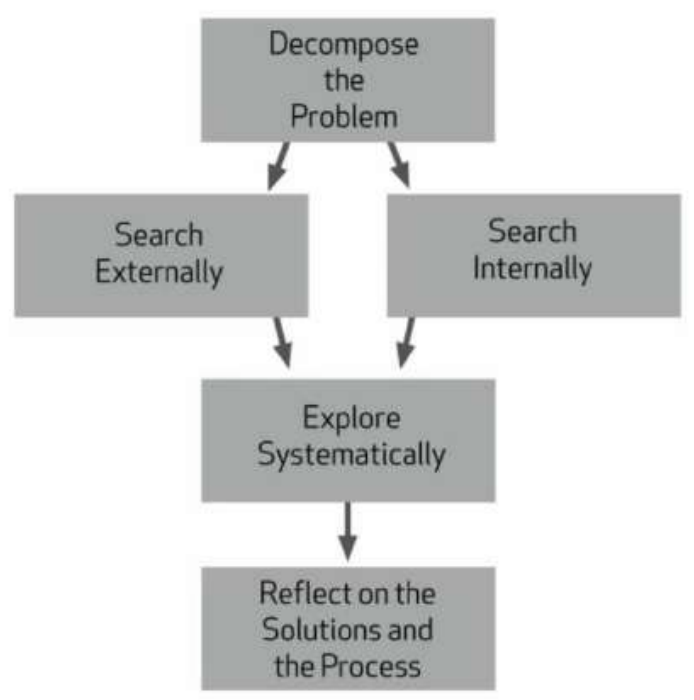

Figure 5. Concept Generation Process

\section{Study case}

Our idea to find a valid proposition (new service) to provide "Approval and disbursal of bank loans to individual within 24 Hours". The target group are low-income people; non-banking people; non-social security services; non-Insurance services. In case of emergencies, they had to accept loans of black market credit with high rate interests. Money requirements are not high, only to solve their current problem.

The our assumptions are: analysis and written problem is from bank's perspective; individual has an existing bank account at the bank providing this loan service; bank has access to a faster payments (real-time) based on the following scheme

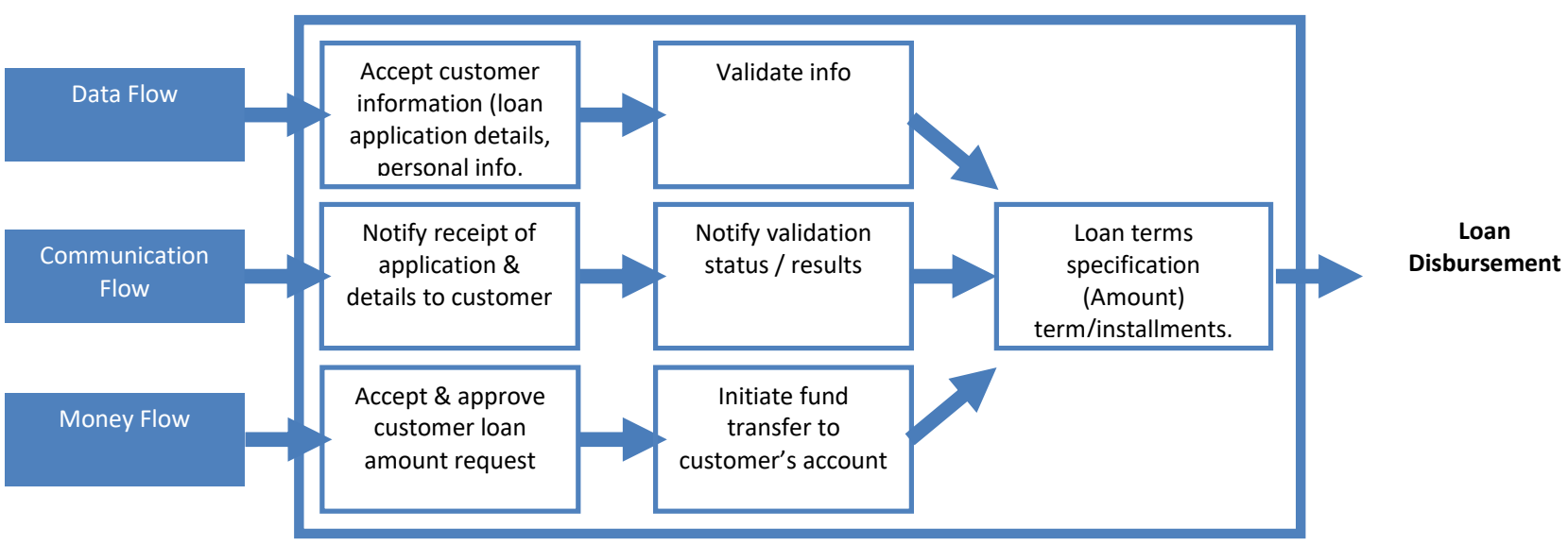

Our idea could be a valid idea or not. The market could or nor validate our proposition. Before that, we need to proceed with the problem decomposition, which means to break the single problem into several sub-problems: data to be communicated and validated efficiency; appropriate and efficient validation process; communication method between customer and bank throughout the loan application and grand process and not in the end timely fund transfer to customer bank account 


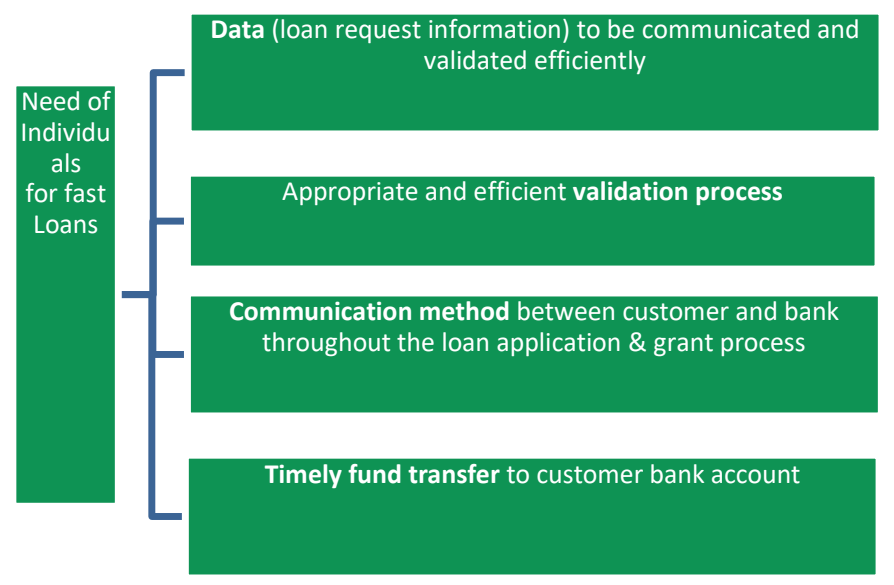

Figure 6. Divided the single problem into several sub-problems

For which sub-problems, the phases of the process "Approval and disbursal of bank loans to individual within 24 Hours", we have individuated a set of solutions.

a) On boarding process. For a robust and secure data (loan request information) submission method we have individuated the following solutions: using Web interface; using the power of Email for the notifications; using Mobile application \& communication; unique Identification Customer Code across all Banks/Financial Institutes; a Third Party Agency to data collection

b) Validation data. To have an appropriate and efficient validation process we have individuated the following solutions: using a web interface; using the email; Unique Identification Customer Code across all Banks/Financial Institutes; SMS code validation phone number; Online / Offline Validation by independent TPIA; Risk assessment by TPIA

c) Communication. We can obtain a responsive communication method throughout the process applying the following solutions: E-mail notifications; in-App notifications \& alerts; Solution; SMS notification; Call notification; Amount of Loan approval depending on the criticality.

d) Transfer of funds. Timely fund transfer to customer bank account could be finalised based on the following solutions: real-time fund transfer scheme; use of non-bank money transfer services; parallel intimation of loan approval to the reason (Hospital/ Repairing shop/Billing entity) for which loan is applied.

Sub-Problem 1
(Onboarding)
Robust and secure data
(loan request
information) submission
method
- Solution 1: Web
interface
- Solution 2: Email
Notifications
- Solution 3: Mobile
application \&
communication
- Unique Identification
Customer Code across
all Banks/Financial
Institutes
- A Third Party Agency to
data collection

\section{Sub-Problem 2 (Validation)}
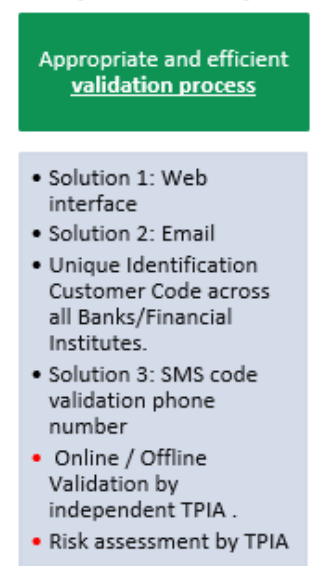

Figure 7. Sub-Problems and their potential solutions

Online / Offline

Validation by

independent TPIA.
Sub-Problem 4 (Communication) (Transfer of funds)

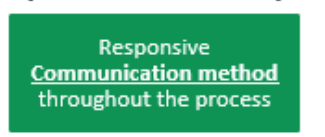

Timelv fund transfer to customer bank account

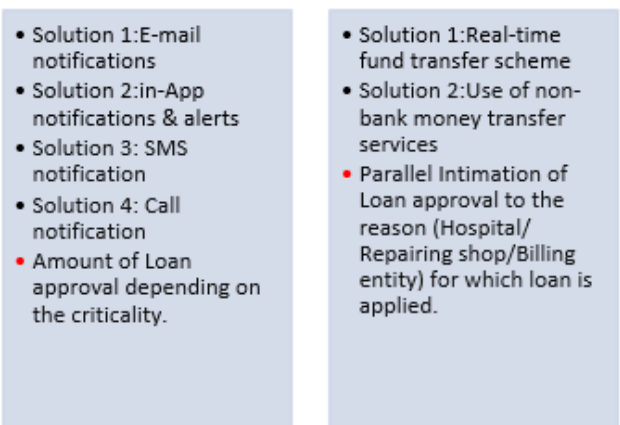

notification

Solution 2:in-App

notifications \& alerts

Solution 4: Ca

notification

approval depending on

the criticality.

entity) for which loan is 
A Service Experience Cycle map for the product/service or Preliminary Cycle Map for fast loan service has drafted here bellow: sudden need of money; Loan application; approval; loan disbursement; pay using loan; repay loan amount;

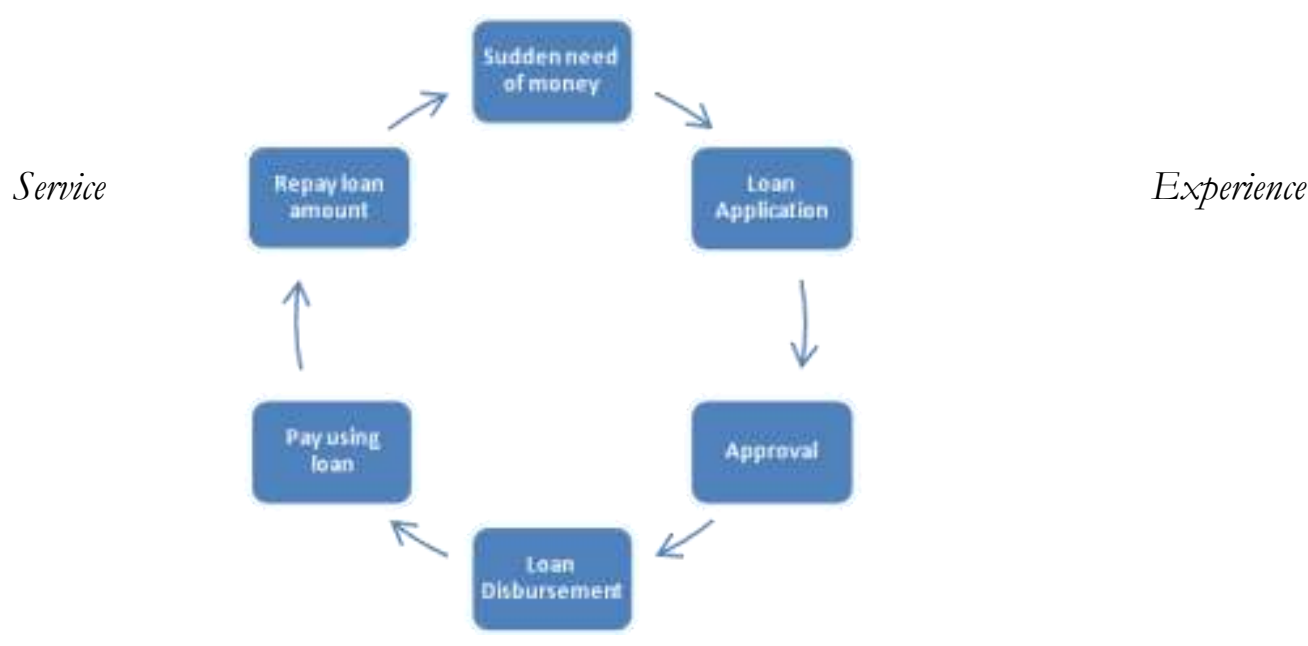

Figure 8. Cycle map for "Fast Loan"

Real-Win-Worth it framework, check out suitable opportunities, and develop a solution that addresses each facet of the framework. We tried to give almost two answers to the following questions: is there a real customer need? Could we win with this opportunity? Is it worthwhile business proposition?
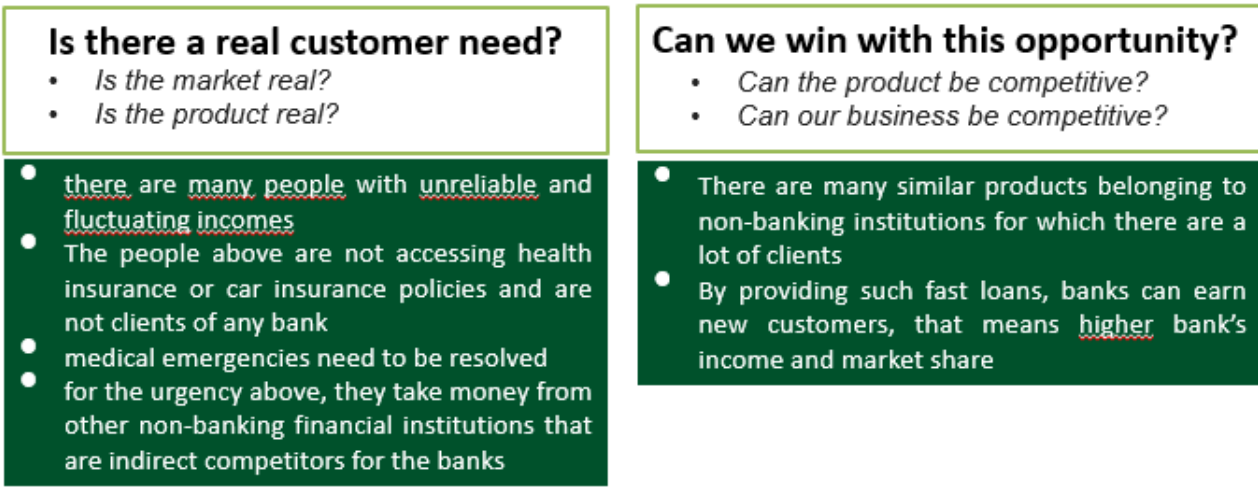

Is it a worthwhile business proposition?

- Will the product be profitable at an acceptable risk?

- Does launching the product make strategic sense?

- The product is self-financing and low risk

- By providing such fast loans, banks can earn many new small customers globally, that means more income and market share

Figure 9. Real-Win-Worth Framework

\section{a. Loan for the true demand}

Stories like Maria's one happened every day in many countries around the world, mainly in developing countries like, East Europe, South America, Africa.

In Developing Countries more than half of the population had a non-formal employment. 
- To Maria, a food seller in Romania, her income is around 100 RON per day (around 20 USD)

- As many Romanian, she and her family dos not have access to Health Services.

- One day, her son Ion has an accident and his arm is break.

- She does not had money to pay that medical expenses. With her level of income and with no formal employment, she does not have a credit card to go ahead.

- She is in a trouble, she has to accept an informal lend with a high rate interest to solve that emergency.

\title{
b. Is it Real?
}

There are many people with unreliable and fluctuating incomes, even in many developed economies. Such population lack creditworthiness, thus often do not have sufficient access to financial services, including the most general insurance and banking services.

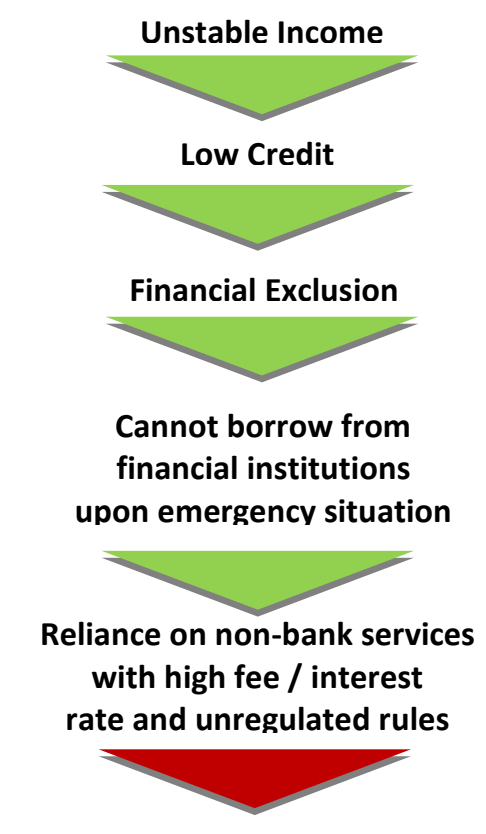

\begin{abstract}
a Real Need of money to individual quickly upon emergency situations with acceptable interest rates
\end{abstract}

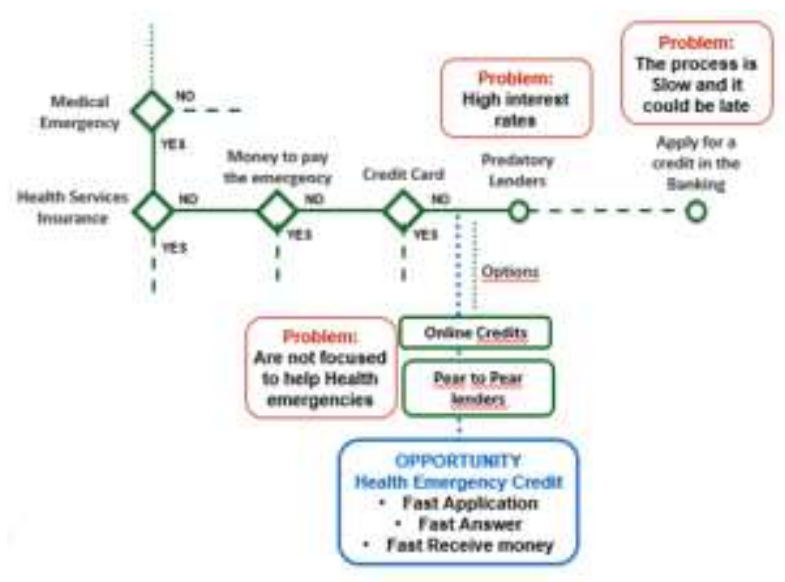




\section{c. Can We Win it?}

"Health Emergency Credit" gives to the people the need of money to solve their health emergencies.

Easy access, quick fills information, alternatives to get money in different places.

We are not validating the credit capacity; we are validating the existence of the necessity.

Ideal Scenario: Clients have a health emergency, they do not have the money, they go to the hospital, they need money, they apply online, they receive money immediately in some autoservice store or supermarket or the check is paid directly and they pay the check. They know that it will help in emergency cases, when nobody want to help them.

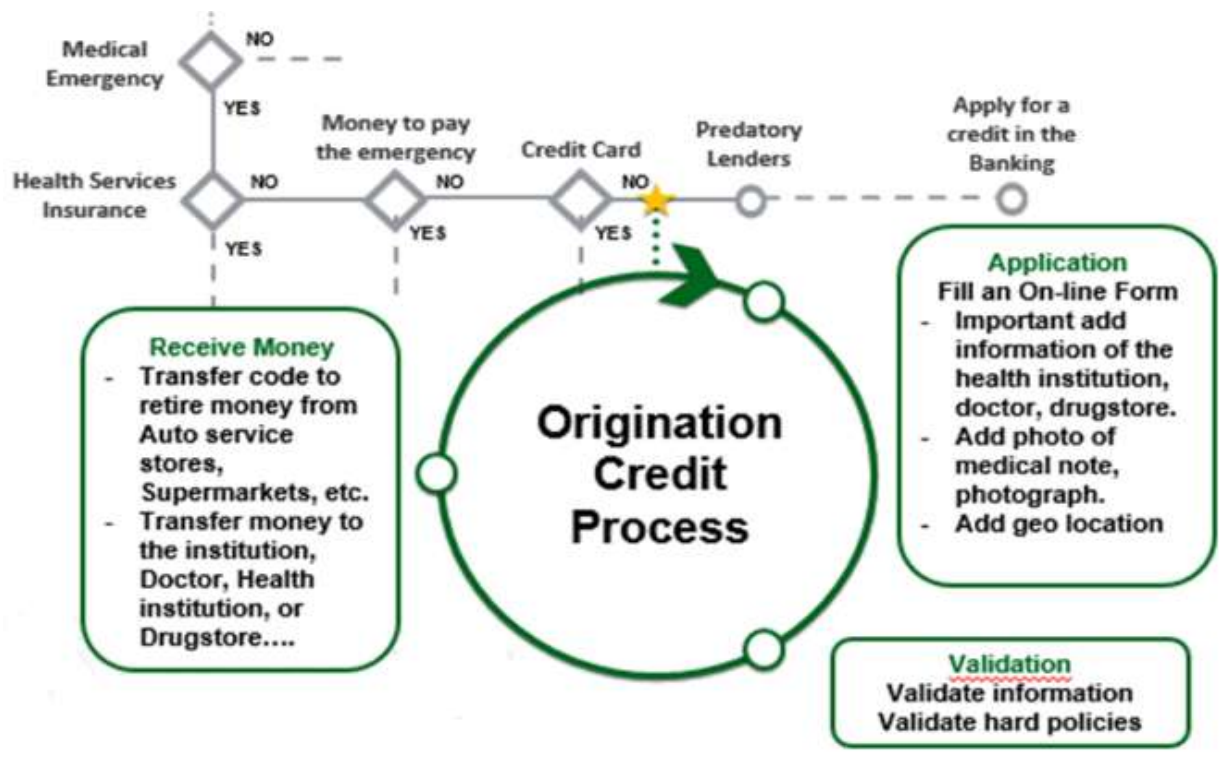

\begin{tabular}{|c|c|c|c|c|c|}
\hline & $\begin{array}{c}\text { Group } 2 \\
\text { Project: } \\
\text { Health } \\
\text { Emergency } \\
\text { Credit }\end{array}$ & $\begin{array}{c}\text { Online } \\
\text { Lending / P2P } \\
\text { Lending }\end{array}$ & $\begin{array}{c}\text { Banking } \\
\text { Credits } \\
\text { (Financial } \\
\text { Insttutions) }\end{array}$ & $\begin{array}{l}\text { Non Banking } \\
\text { Microcredits }\end{array}$ & $\begin{array}{l}\text { Lending } \\
\text { Predator }\end{array}$ \\
\hline $\begin{array}{l}\text { Online application (any place) } \\
\text { Paper less } \\
\text { Easy start application } \\
\text { Fast Answer } \\
\text { Regulated Insttution } \\
\text { High Interests } \\
\text { Focused on Health emergencies } \\
\text { High tech validate information }\end{array}$ & $\begin{array}{l}8 \\
\varnothing \\
6 \\
6 \\
8 \\
8 \\
\varnothing\end{array}$ & $\begin{array}{l}6 \\
6 \\
6 \\
6 \\
8 \\
8 \\
8\end{array}$ & $\begin{array}{l}\text { (2) } \\
\text { (2) } \\
\text { (2) } \\
8 \\
8 \\
8\end{array}$ & 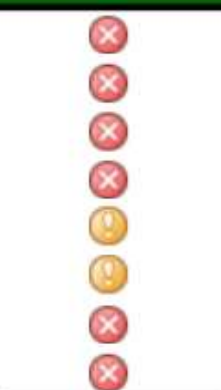 & $\begin{array}{l}8 \\
8 \\
0 \\
0 \\
8 \\
8 \\
8\end{array}$ \\
\hline
\end{tabular}




\section{d. Is it Worth it?}

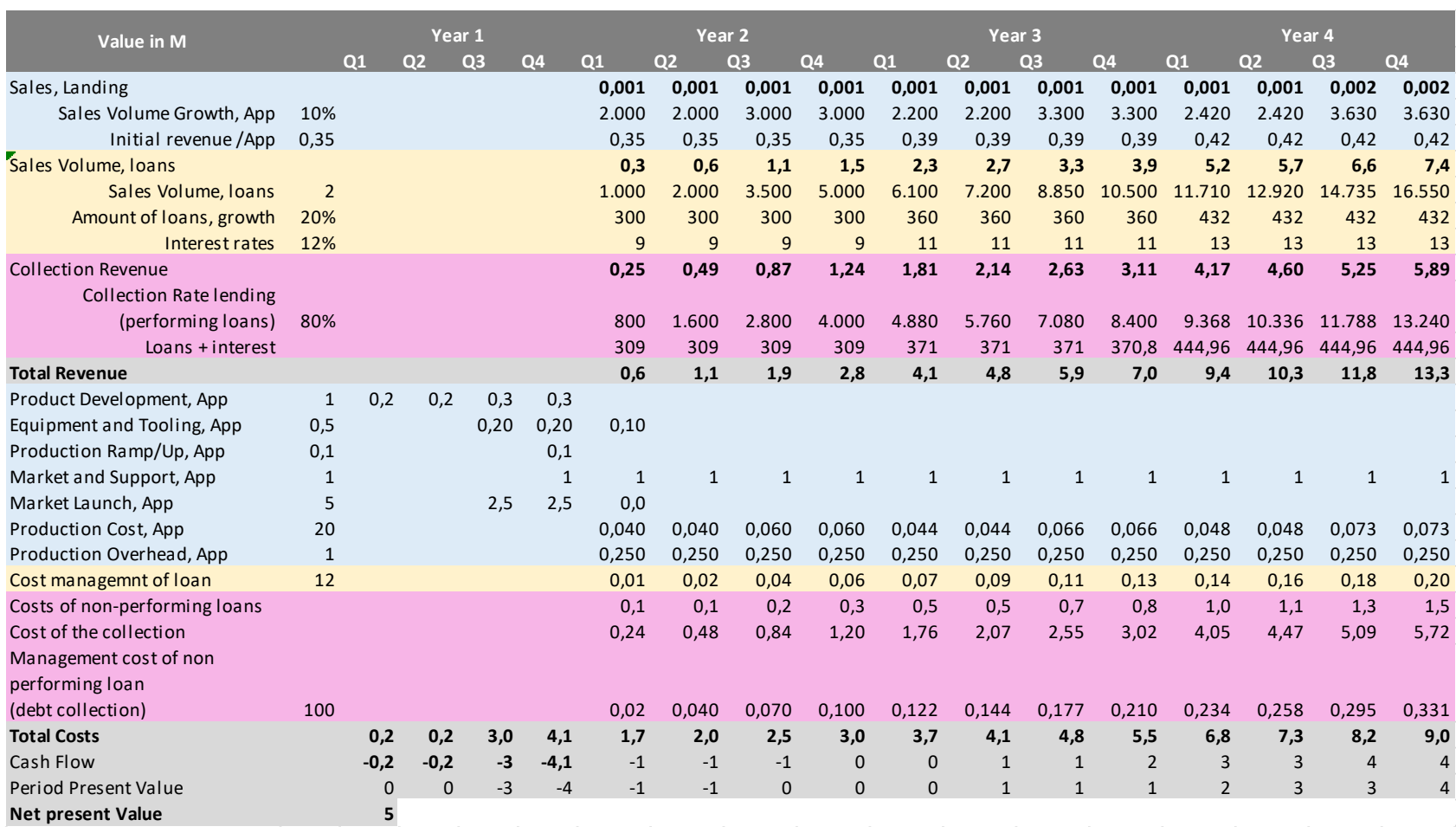

\section{Recommendation}

Our solution concept is based on the true demand of the global under banked population.

We believe that a real opportunity exists, and that the solution provider can leverage its status as a regulated financial institution to provide safety and security of the service.

From our preliminary NPV analysis, we found that, although the NPL is expected to be higher than traditional loans, the concept could survive by achieving enough increase in customer and service volume.

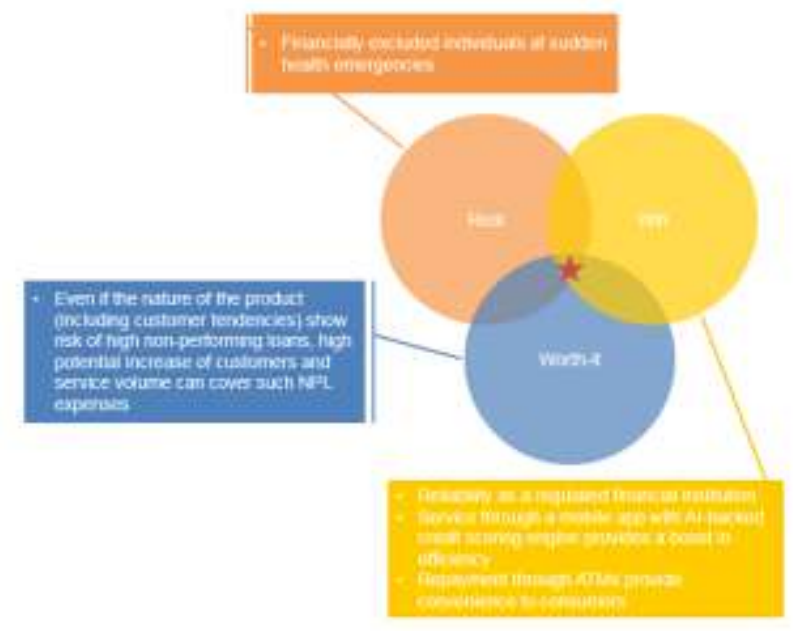

In order to further explore the solution design details, we recommend that a product prototype is built targeted at a particular area, and rolled out for a defined period.

Such POC will help us to understand the viability of the solution more realistically, a more detailed financial analysis, and enable risk modelling as required and risk models. 


\section{Conclusions}

Design Thinking refers to the cognitive, strategic and practical processes by which design concepts (proposals for new products, buildings, machines, etc.) are developed by designers and/or design teams. Many of the key concepts and aspects of design thinking have been identified through studies, across different design domains, of design cognition and design activity in both laboratory and natural contexts.

Design Thinking is also associated with prescriptions for the innovation of products and services within business and social contexts. Some of these prescriptions have been criticized for oversimplifying the design process and trivializing the role of technical knowledge and skills.

Historically, designers tended to be involved only in the later parts of the process of new product development, focusing their attention on the aesthetics and functionality of products. Many businesses and other organisations now realise the utility of embedding design as a productive asset throughout organisational policies and practices, and Design Thinking has been used to help many different types of business and social organisations to be more constructive and innovative.

In the 2000s there was a significant growth of interest in design thinking as a catalyst for gaining competitive advantage within business, but doubts around design thinking as a panacea for success have also been expressed. Designers bring their methods into business either by taking part themselves from the earliest stages of product and service development processes or by training others to use design methods and to build innovative thinking capabilities within organisations.

Design Thinking has been central to user-centered design and human-centered design - the dominant methods of designing human-computer interfaces - for over 40 years. Design thinking is also central to recent conceptions of software development in general.

\section{References}

[1] Brown, Tim (2009) - Tim Brown urges designers to think big (YouTube). TED

[2] Brown, Tim, Kätr, Barry (2009) - Change by Design: How Design Thinking Transforms Organizations and Inspires Innovation. New York: Harper Business

[3] Brown, Tim (2008) - Design Thinking, Harvard Business Review, June 2008, pp. 85-92

[4] Cross, Nigel (2001) - Design Cognition: Results from Protocol and other Empirical Studies of Design Activity, in C. Eastman, M. McCracken and W. Newstatter (eds.) Design Knowing and Learning: Cognition in Design Education, Elsevier, Oxford, 2001, pp. 79-103

[5] Dorst, Kees (2012) - Frame Innovation: Create new thinking by design. Cambridge, MA: MIT Press

[6] Kelley, Tom, Littman, Jonathan (2001) - The Art of Innovation: Lessons in Creativity from IDEO, America's leading design firm

[7] Kolko, J. (2018) - The divisiveness of design thinking." ACM Interactions, May-June, 2018: http:/ / interactions.acm.org/archive/view/ may-june-2018/ the-divisiveness-of-design-thinking

[8] Myerson, Jeremy (2001) - IDEO: Masters of Innovation. New York: teNneues

[9] Norman, Donald A. (1986) - User Centered System Design. Taylor \& Francis. doi:10.1201/b15703

[10] Ralph, Paul (2015) - The Sensemaking-Coevolution-Implementation Theory of software design". Science of Computer Programming. 101: 21-41. arXiv:1302.4061. doi:10.1016/j.scico.2014.11.007.

[11] Rowe, G. Peter (1987) - Design Thinking. Cambridge: The MIT Press

[12] Simon, Herbert (1969) - The Sciences of the Artificial. Cambridge: MIT Press.

[13] Visser, $W$ (2006) - The cognitive artifacts of designing, Lawrence Erlbaum Associates

[14] Design Thinking Is a Boondoggle, The Chronicle of Higher Education. 2018-05-21. Retrieved 2018-0706.

[15] Product Design and Development (Irwin Marketing), 6th Edition, by Karl Ulrich and Steven Eppinger (Refer to Chapters 7, 8, and 9)

[16] http:/ / wmw.designorate.com/ideation-design-thinking-tools

[17] http:// creatingminds.org/tools/tools_ideation.htm

[18] https:// hbr.org/2011/11/ bow-to-think-creatively.html. 
International Conference "Risk in Contemporary Economy" ISSN-L 2067-0532 ISSN online 2344-5386 $\mathrm{XX}^{\text {th }}$ Edition, 2019, Galati, Romania,

"Dunarea de Jos" University of Galati, Romania - Faculty of Economics and Business Administration

[19] bttps:/ / bbr.org/2015/08/the-emotions-that-make-us-more-creative.

[20] bttp:// www.mckinsey.com/ business-functions/strategy-and-corporate-finance/our-insights/seven-steps-tobetter-brainstorming.

[21] bttps: / wmw.interaction-design.org/literature/ article / 5-stages-in-the-design-thinking-process 